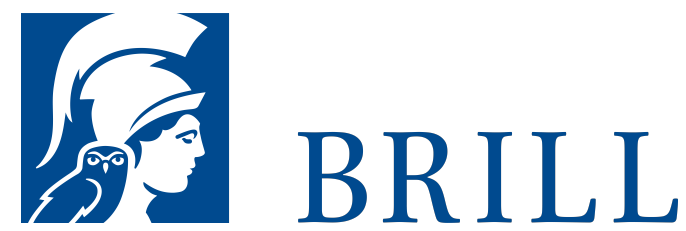

\title{
Stimmung, Emotion, Atmosphäre
}

Phänomenologische Untersuchungen zur Struktur der menschlichen Affektivität

Author: Thomas Bulka

In den vergangenen Jahren sind die Emotionen und Stimmungen des Menschen immer stärker in den Fokus der philosophischen Aufmerksamkeit gerückt. Während jedoch Emotionstheorien, die sich an den Begrifflichkeiten und Kategorien der Psychologie orientieren, Emotionen, Stimmungen und auch Atmosphären als rein subjektive mentale Phänomene auffassen, kann die phänomenologische Beschreibung diesen Interpretationsansatz nicht stützen. Das vorliegende Buch stellt sich darum die Aufgabe, das Verhältnis von Atmosphären, Stimmungen und Emotionen neu zu bestimmen. Im Zentrum der Untersuchung steht dabei das Spannungsfeld von Affektivität und Wahrnehmung. Dieser Ansatz erlaubt es nicht nur, rein mentalistische Konzeptionen der Stimmungen und Emotionen zu kritisieren, sondern darüber hinaus auch, die gesamte leiblich fundierte Existenz des Menschen als stets affektiv vorgeprägt auszuweisen. Diese Grundaffektivität verwirklicht sich, so die These des Buches, im steten Wechsel von Situationserfahrung und Gegenstandswahrnehmung und bildet die Voraussetzung für die Orientierung des Menschen in einer von Bedeutsamkeit erfüllten Welt.

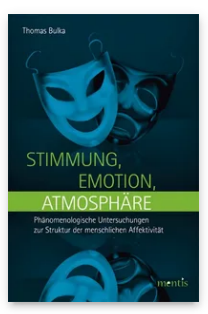

Pages: 366 Seiten Language: German

Subjects: General, Philosophy

Publisher: Brill | mentis

E-Book (PDF) Released online: o5 May 2015 ISBN: $978-3^{-}$ 95743-898-o List price Paperback Publication date: o5 May 2015 ISBN: 978-395743-0o9-o List price 
For more information see brill.com

Order information: Order online at brill.com +44330 333 0049 | customerservices@brill.com Submission information: brill.com/authors

Titles published by Brill | Fink, Brill | mentis or Brill | Schöningh: +49(o)715413279216| brill@brocom.de 